\title{
The $\mathrm{S}_{2}$ State of the Oxygen-Evolving Complex of Photosystem II Explored by QM/MM Dynamics: Spin Surfaces and Metastable States Suggest a Reaction Path Towards the $S_{3}$ State ${ }^{\star *}$
}

\author{
Dr. Daniele Bovi", \\ Dipartimento di Fisica, Sapienza-Università di Roma, P.le Aldo Moro 5, 00185 Roma (Italy) \\ Dr. Daniele Narzi ${ }^{\#}$, and \\ Dipartimento di Fisica, Sapienza-Università di Roma, P.le Aldo Moro 5, 00185 Roma (Italy) \\ Prof. Dr. Leonardo Guidoni \\ Dipartimento di Fisica, Sapienza-Università di Roma, P.le Aldo Moro 5, 00185 Roma (Italy); \\ Dipartimento di Scienze Fisiche e Chimiche, Università degli Studi dell'Aquila Via Vetoio 2, \\ Coppito, L’Aquila (Italy), leonardo.guidoni@univaq.it
}

\# These authors contributed equally to this work.

\section{Keywords}

ab initio calculations; density functional calculations; Kok cycle; photosystem II; water splitting

\begin{abstract}
One of the key steps in photosynthetic solar-energy conversion performed by plants, algae, and cyanobacteria is the splitting of water into molecular oxygen and hydrogen equivalents. ${ }^{[1]}$ To achieve this challenging task photosynthetic organisms use a protein complex that remained almost unchanged during the evolution in the last two and a half billion years: the photosystem II (PSII). The reaction proceeds by the accumulation of four oxidizing equivalents on the $\left\{\mathrm{Mn}_{4} \mathrm{CaO}_{5}\right\}$ cluster through five $\left(\mathrm{S}_{0}-\mathrm{S}_{4}\right)$ oxidation states that are sequentially attained during water splitting (Kok cycle). ${ }^{[2]}$ The deep understanding of the way nature has found to perform this difficult task efficiently has a great relevance not only for biology but also for inspiring the development of biomimetic artificial systems that can be used to store solar energy in an environmentally friendly way. ${ }^{[3]}$ Atomic details of the structure of the oxygen-evolving complex (OEC) of PSII have been revealed by extended Xray absorption fine structure (EXAFS) experiments and by X-ray crystallography at increasing resolution levels. ${ }^{[4]}$ However, the accurate position of the $\left\{\mathrm{Mn}_{4} \mathrm{CaO}_{5}\right\}$ cluster atoms and its ligands emerged only when a X-ray structure at $1.9 \AA$ A resolution became accessible. ${ }^{[5]}$ However, the effect of a possible X-ray photo-reduction, in particular on the characterization of the Kok's state described by this structure and on the unrealistic bond lengths between the oxygen atom $\mathrm{O} 5$ and the two manganese ions Mn1 and Mn4, is matter of debate. ${ }^{[6]}$ Additionally, important contributions to the structure refinement came from theoretical studies. ${ }^{[6 \mathrm{~b}, 7]}$
\end{abstract}

Apart from a detailed characterization of the molecular structure of the OEC, an exact description of the water-splitting catalytic mechanism cannot leave aside an accurate

\footnotetext{
** This work was supported by the ERC grant No. 240624. QM/MM: quantum mechanics/molecular mechanics. Computational resources were provided by CINECA and by the Caliban-HPC computer centre of the University of L'Aquila.

2013 Wiley-VCH Verlag GmbH \& Co. KGaA, Weinheim

Supporting information for this article is available on the WWW under http://dx.doi.org/10.1002/anie.201306667.
} 
investigation of the electronic and magnetic properties characterizing the $\left\{\mathrm{Mn}_{4} \mathrm{CaO}_{5}\right\}$ cluster. In the past three decades electron paramagnetic resonance (EPR) experiments represented an extremely effective tool to explore such properties. In particular the $S_{2}$ state has been investigated in detail since the early 1980 s. ${ }^{[8]}$ The $S_{2}$ EPR signals include a multiline signal (MLS) centered at $g=2.0$ and a broad signal centered at $g \approx 4.1$ (reviewed by Haddy ${ }^{[9]}$ ). The MLS is indicative of a ground-state characterized by a spin $S=1 / 2$ whereas signals at $g \geq 4.1$ seem to be consistent with a spin $S \geq 5 / 2$. Intriguingly the presence of the two signals was shown to depend on the temperature as well as on a variety of conditions in the sample preparation. In particular Casey and Sauer reported that the signal at $\mathrm{g} \approx 4.1$ can be generated by illumination at $130 \mathrm{~K} \cdot{ }^{[8 c]}$ The subsequent warming of the sample at $200 \mathrm{~K}$ leads to a conversion of the signal back to the MLS. Boussac et al. ${ }^{[8 \mathrm{k}]}$ showed that if the illumination is carried out on the untreated PSII in dark-adapted membranes filtering out the near-infrared component at $130 \mathrm{~K}$, only the MLS is detected. Thereafter the state responsible for the MLS was converted into that corresponding to the $g \approx 4.1$ signal by excitation with near-infrared light at $150 \mathrm{~K}$. Finally when temperatures of $200 \mathrm{~K}$ or more are reached, only the MLS is observed. Beside the large number of experiments performed on PSII in the past xsyears, theoretical studies have provided new insights into the structural, electronic, and magnetic properties of PSII. ${ }^{[6,7,10]}$ In a recent contribution Pantazis et al. ${ }^{[11]}$ proposed the existence of two interconvertible structures consistent with the $S_{2}$ state and generating the two EPR signals. The two structures differ mainly in the position of the oxygen atom O5 (see inset in Figure 1), which is, in one case (Model A), bound to Mn4 to form a $S=1 / 2$ spin state responsible for the MLS, and in the second case (Model B), to Mn1 in a $S=5 / 2$ state associated with the $g \approx 4.1$ signal. The close energies and the low barriers reported for gas-phase models of the Model A and Model $\mathrm{B}$, referred hereafter as $\mathrm{S}_{2}{ }^{\mathrm{A}}$ and $\mathrm{S}_{2}{ }^{\mathrm{B}}$, suggest they can interconvert. Furthermore, it would be important for calculations to consider the effect of the full surrounding protein environment as well as the effect of molecular dynamics. Beside the importance of simulating temperature effects, the dynamic description is also crucial to escape from the local energy minima of such a complex hydrogen-bonding network. ${ }^{[12]}$ Both the temperature and environmental effects can be explicitly taken into account by ab initio molecular dynamics (AIMD) simulations performed within a quantum mechanics/molecular mechanics framework. ${ }^{[6 \mathrm{a}, 13]}$ Herein we will characterize, by AIMD using the CP2K package, ${ }^{[13 f, g]}$ the interconversion between the two states on different spin surfaces from the electronic, structural, and thermodynamic point of view. This approach will clarify the role of the different spin states on the stability of the two minima and on the transition between them, giving a framework for the interpretation of the rich literature available on the different stable and metastable states of $S_{2}$. In addition, our simulations suggest a new structural model for the $S_{2}$ to $S_{3}$ state transition, providing new insights on the water-splitting mechanism.

The QM/MM computational setup was based on the recent high-resolution crystal structure ${ }^{[5]}$ of PSII. We treated at the DFT+U level a portion of the system consisting of 202 atoms around the $\left\{\mathrm{Mn}_{4} \mathrm{CaO}_{5}\right\}$ cluster (see Figure 1). The classical system consists of the D1, D2 and CP43 polypeptide chains and the neighboring cofactors and water molecules present in the structure. Convergence tests on quantum regions of similar sizes recently confirmed the reliability of our model. ${ }^{[14]}$ As starting positions for both $\mathrm{S}_{2}{ }^{\mathrm{A}}$ and $\mathrm{S}_{2}{ }^{\mathrm{B}}$ models of the $\left\{\mathrm{Mn}_{4} \mathrm{CaO}_{5}\right\}$ cluster we used the coordinates reported by Pantazis et al. ${ }^{[11]}$ Further details on methods, setup, and computational methods are provided in Supporting Information.

We analyzed the two minima $\mathrm{S}_{2}{ }^{\mathrm{A}}$ and $\mathrm{S}_{2}{ }^{\mathrm{B}}$. In the $\mathrm{QM} / \mathrm{MM}$ optimized structures the spin ground-state for $\mathrm{S}_{2}{ }^{\mathrm{A}}$ corresponds to low spin (LS) $S=1 / 2$ and for $\mathrm{S}_{2}{ }^{\mathrm{B}}$ corresponds to high spin (HS) $S=5 / 2$, in agreement with previous results in the gas phase ${ }^{[11]}$ (details concerning 
the broken symmetry states are described in Table S1). In particular we found that in $\mathrm{S}_{2}{ }^{\mathrm{A}}$ the LS (ground) state is $0.5 \mathrm{kcal} \mathrm{mol}^{-1}$ more stable than the HS state. Conversely, in the $\mathrm{S}_{2}{ }^{\mathrm{B}}$ state, we estimated an energy gap of $0.7 \mathrm{kcal} \mathrm{mol}^{-1}$ between the HS (ground) state and the LS state. For both states the optimizations were followed by $15 \mathrm{ps}$ of QM/MM ab initio molecular-dynamics simulations at $T=298 \mathrm{~K}$. Both models were found to be fairly stable, each Mn atom maintaining its initial coordination number and its spin population. Geometric properties of the two models, as calculated along the QM/MM dynamics, are reported in Table S2 and compared with values extracted from the optimized structures. In addition to the different coordination and oxidation states of the $\mathrm{Mn} 1$ and $\mathrm{Mn} 4$ ions, the $\mathrm{S}_{2}{ }^{\mathrm{A}}$ and the $\mathrm{S}_{2}{ }^{\mathrm{B}}$ models are characterized by the fact that the average Mn1-Mn4 distance increases by about $0.1 \AA$ on passing from $\mathrm{S}_{2}{ }^{\mathrm{A}}$ to $\mathrm{S}_{2}{ }^{\mathrm{B}}$. The room-temperature fluctuations are rather large revealing that, within $\mathrm{S}_{2}{ }^{\mathrm{B}}$, distances larger than $5.4 \AA$ are significantly populated during the QM/MM dynamics (Figure S2). This evidence might have important consequences on the rearrangement of binding water molecules and on the water splitting mechanism, as will be discussed below.

To investigate the relative stability of the two states and to estimate the free energy profiles for the $\mathrm{S}_{2}{ }^{\mathrm{A}}$ and $\mathrm{S}_{2}{ }^{\mathrm{B}}$ interconversion we carried out thermodynamic integration using as reaction coordinate $\xi$ the difference between Mn4-O5 and Mn1-O5 distances (see Supporting Information). Along the constrained dynamics on the LS surface $\left(S_{Z}=1 / 2\right)$ we observed a decrease of the Mn4-Mn1 distance as the systems approach the transition state, to a minimum of $4.5 \AA$ (Figure 2a). At the same time, as shown in Figure $2 b$, the coordination number of $\mathrm{Mn} 1$ and $\mathrm{Mn} 4$ exchanges (thick lines) and a simultaneous inversion of the spin populations (dashed lines) of the two Mn ions occurs, consistently with a transition from $\mathrm{Mn} 1^{\mathrm{III}} \mathrm{Mn} 4^{\mathrm{IV}}$ to $\mathrm{Mn} 1^{\mathrm{IV}} \mathrm{Mn} 4^{\mathrm{III}}$ states. The free-energy profiles for different spin states reported in Figure 2c show that the interconversion always occurs on the lowspin surface, also in the $S_{2}{ }^{B}$ to $S_{2}{ }^{A}$ case, where, despite $S_{Z}=5 / 2$ being the ground state, it has a higher barrier.

The overall transition from $\mathrm{S}_{2}{ }^{\mathrm{A}}$ low spin to $\mathrm{S}_{2}{ }^{\mathrm{B}}$ high spin states is slightly endergonic, $\left(\Delta G \approx 1.1 \mathrm{kcal} \mathrm{mol}^{-1}\right)$ with an activation barrier of $\Delta G^{\#} \approx 10.6 \mathrm{kcal} \mathrm{mol}^{-1}$, which is slightly larger than a previous estimate (i.e. $\Delta G^{\#}<9.0 \mathrm{kcal} \mathrm{mol}^{-1[11]}$ ). Assuming that the relation between the Gibbs energy of activation and the reaction rate constant can be described by the Eyring-Polanyi equation, a barrier of $10.6 \mathrm{kcal} \mathrm{mol}^{-1}$ would correspond at room temperature to an half-life time $\tau_{\mathrm{AB}} \approx 1-10 \mu \mathrm{s}$, indicating that in these conditions the interconversion is thermally activated. Conversely, at lower temperatures $(T<130 \mathrm{~K})$ the half-life time becomes $\tau_{\mathrm{AB}}>1$ day, denoting that the crossing between the two states is kinetically inactivated on the typical time and temperature ranges of cryogenic EPR experiments. A summarizing diagram is reported in Figure 3a. The endergonicity of the $\mathrm{S}_{2}{ }^{\mathrm{A}}$ to $\mathrm{S}_{2}{ }^{\mathrm{B}}$ transition and the height of the kinetic barrier between the two states have important consequences for the interpretation of previous experiments observing the transition between the EPR multi-line signal, associated with $\mathrm{S}_{2}{ }^{\mathrm{A}}$, and the $g \approx 4.1$ signal, assigned to $\mathrm{S}_{2}{ }^{\mathrm{B}} \cdot{ }^{[11,15]}$

According to our free-energy landscape, at room temperature (and in general for $T \geq 200 \mathrm{~K}$ ) both $\mathrm{S}_{2}{ }^{\mathrm{A}}$ and $\mathrm{S}_{2}{ }^{\mathrm{B}}$ states are appreciably populated. When cryogenic EPR experiments are recorded, the sample is brought to $10 \mathrm{~K}$ and during the cooling time only the thermodynamically more stable $\mathrm{S}_{2}{ }^{\mathrm{A}}$ state remains populated leading to the MLS. ${ }^{[8 f, k, 9]}$ This process is described in Figure 3b1. When near-infrared light is used at low temperatures ( $T<$ $130 \mathrm{~K}$ ), the barrier can still be overcome, by either a spin-allowed d-d transition in the $\mathrm{Mn}^{\mathrm{III}}$ ion or a charge transfer within the $\left\{\mathrm{Mn}_{4} \mathrm{CaO}_{5}\right\}$ cluster ${ }^{[9]}$, thus resulting in the simultaneous population of both the $\mathrm{S}_{2}{ }^{\mathrm{A}}$ and $\mathrm{S}_{2}{ }^{\mathrm{B}}$ states. At variance with the situation for $T \geq 200 \mathrm{~K}$ the estimated half-life time is $\tau_{\mathrm{AB}} \approx 10-10^{2}$ hours, therefore the thermal interconversion is 
kinetically inhibited. In these conditions both states remain populated when samples are brought to $10 \mathrm{~K}$ for EPR measurements, leading to the appearance of the $g=4.1$ signal as reported in the experiments from Boussac et al. ${ }^{[\mathrm{k}, 1]}$ (Figure 3b2). A further increase of temperature, such as in Ref. [8c,k], brings $\tau_{\mathrm{AB}}$ to the ms time range, therefore allowing the population to relax to the most thermodynamically stable state during the EPR experiments, as shown in Figure 3b3. When an infrared filter is applied to dark-adapted states at $130 \mathrm{~K}$ only $\mathrm{S}_{2}{ }^{\mathrm{A}}$ is selected, ${ }^{[8 \mathrm{k}]}$ since at this temperature the interconversion is not thermally activated, consistently with our scheme (Figure 3b4). The behavior of other similar experimental procedures reported in literature can be interpreted using the same scheme, as shown in Figure 3b5/6. The landscape of the spin states, the value of the calculated freeenergy barrier, and the slight endergonicity of the interconversion seems to provide a consistent scheme in which to rationalize the temperature and procedure dependence of several experiments.

Additional information about the $\mathrm{S}_{2}{ }^{\mathrm{A}}$ to $\mathrm{S}_{2}{ }^{\mathrm{B}}$ transition is gained from a careful analysis of the Mn coordination (red solid line in Figure $2 b$ ). We observe that during the dynamics simulation one additional water molecule can be occasionally added to the $\mathrm{Mn} 4{ }^{\mathrm{III}}$ coordination shell, close to the $\mathrm{S}_{2}{ }^{\mathrm{B}}$ minimum. We explored the room-temperature stability of such a hexacoordinate structure by an additional ab initio QM/MM dynamics simulation performed constraining the reaction coordinate to assume a value of $\xi=1.6 \AA$. In this new structure, the W3 water molecule, originally coordinated to the calcium atom (Figure 4a), becomes bound to $\mathrm{Mn} 4$ at a distance of $2.3 \AA$. Interestingly this provoked a rearrangement of the surrounding water molecules which move concertedly in single file as shown in Figure 4. The coordination of the W3 molecule with the Mn4 ion is preceded by the coordination of a neighboring water molecule (namely Wa) to the calcium ion and the subsequent movement of the water molecule $\mathrm{Wb}$ into the original position of Wa. This coordination pattern with $\mathrm{Mn} 4{ }^{\mathrm{III}}$ and the other three $\mathrm{Mn}^{\mathrm{IV}}$ centers of the cluster hexacoordinate, is maintained after the constraint release during $4.0 \mathrm{ps}$ of dynamics carried out in both the HS and LS states. During these simulations the distance between the Mn4 ${ }^{\mathrm{III}}$ and the $\mathrm{Mn} 1^{\mathrm{IV}}$ centers increases up to $5.5 \AA$ allowing the oxygen atom of $\mathrm{W} 3$ to undergo large oscillations, reaching a minimum distance of $2.5 \AA$ from the O5 atom. The observed hexacoordination of the $\mathrm{Mn}^{\mathrm{III}}$ center may additionally have important implications for the formation of the $S_{3}$ state, probably favoring the oxidation of Mn4 by Tyr161. Supposing an oxidation number of IV for all the Mn ions in the $S_{3}$ state, ${ }^{[16]}$ such a conformation with all the manganese centers hexacoordinate could be regarded as a precursor of the $S_{3}$ state. The insertion of a water substrate molecule in the $S_{2}$ to $S_{3}$ transition was already suggested in recent studies. ${ }^{[15,17]}$ Additionally, in an alternative to previously proposed mechanisms ${ }^{[10 \mathrm{~d}, \mathrm{e}]}$ our calculations show that the originally calcium-coordinated water W3 may serve as a substrate for oxygen formation after becoming coordinated to Mn4 during the $S_{2}$ to $S_{3}$ transition.

The combination of our results and the available EPR data may have important implications on the water-splitting mechanism. The presence of two EPR signals representative for the $\mathrm{S}_{2}$ state was interpreted from time to time as an indication of either the $g \approx 4.1$ signal as being that of the precursor state of the low-spin state ${ }^{[8 \mathrm{c}]}$ or the contrary. ${ }^{[8 \mathrm{k}]}$ Recently, owing to the almost isoenergetic nature of the two states $\mathrm{S}_{2}{ }^{\mathrm{A}}$ and $\mathrm{S}_{2}{ }^{\mathrm{B}}$, it was also suggested that the transition between the $S_{2}$ and $S_{3}$ state could proceed through different possible nonexclusive pathways. ${ }^{[11]}$ The dynamic characterization, reported herein, strongly suggests that the transition between the $S_{1}, S_{2}$, and $S_{3}$ states should pass through the prior formation of a $S_{2}$ state characterized by a conformation with a low-spin ground-state $\left(S_{2}{ }_{L S}\right)$. Subsequently the $\left\{\mathrm{Mn}_{4} \mathrm{CaO}_{5}\right\}$ cluster undergoes a structural change reaching the conformation with a high-spin ground-state $\left(\mathrm{S}_{2}{ }^{\mathrm{B}} \mathrm{HS}\right)$, a hypothesis recently proposed by Cox and Messinger. ${ }^{[17 b]}$ This path towards the $S_{3}$ state is corroborated by the increased Mn1- 
$\mathrm{Mn} 4$ distance found in $\mathrm{S}_{2}{ }^{\mathrm{B}}$, thus promoting the coordination of the Mn4 ion with an additional water molecule. Moreover, the dynamic investigation of this process revealed that the water channel terminating at the calcium ion may serve as a substrate delivery channel.

Summarizing, we provide new insights on the intricate puzzle represented by the large amount of historical and recent EPR experiments on the $S_{2}$ state. As already suggested by Boussac et al., ${ }^{[8 \mathrm{k}]}$ the appearance of the $g \approx 4.1$ signal at $T \approx 130 \mathrm{~K}$ can be interpreted as the occurrence of two distinct phenomena: first the formation of the $S_{2}$ state associated with the multiline signal and in the second moment the subsequent conversion of the $\mathrm{S}_{2}$ state into the $g \approx 4.1$, as a result of the crossing of the energy barrier triggered by excitation with infrared

light. In this respect the $\mathrm{S}_{2}{ }^{\mathrm{A}} \mathrm{LS}$ state represents a precursor of the $\mathrm{S}_{2}{ }^{\mathrm{B}} \mathrm{HS}$ state in the direction of the $S_{3}$ formation. Our calculations also suggest the existence of a subsequent intermediate state characterized by the presence of four hexacoordinate manganese ions. Such a conformation appears to be a reasonable candidate as a precursor of a $\mathrm{S}_{3}$ state, consistent with recent theoretical studies ${ }^{[18]}$ and gives the opportunity for further interpretation of the available experimental data. ${ }^{[17 b, 19]}$ Characterization of this novel intermediate state from structural, thermodynamic, and a magnetic point of view is in progress.

\section{Supplementary Material}

Refer to Web version on PubMed Central for supplementary material.

\section{References}

[1]. a) Rutherford AW. Trends Biochem. Sci. 1989; 14:227-232. [PubMed: 2669240] b) McEvoy JP, Brudvig GW. Chem. Rev. 2006; 106:4455-4483. [PubMed: 17091926] c) Renger G, Renger T. Photosynth. Res. 2008; 98:53-80. [PubMed: 18830685] d) Barber J. Chem. Soc. Rev. 2009; 38:185-196. [PubMed: 19088973] e) Grundmeier A, Dau H. Biochim. Biophys. Acta Bioenerg. 2012; 1817:88-105.f) Dau H, Zaharieva I, Haumann M. Curr. Opin. Chem. Biol. 2012; 16:3-10. [PubMed: 22387134]

[2]. a) Kok B, Forbush B, McGloin M. Photochem. Photobiol. 1970; 11:457-475. [PubMed: 5456273] b) Dau H, Haumann M. Biochim. Biophys. Acta Bioenerg. 2007; 1767:472-483.

[3]. a) Kanan MW, Nocera DG. Science. 2008; 321:1072-1075. [PubMed: 18669820] b) Reece SY, Hamel JA, Sung K, Jarvi TD, Esswein AJ, Pijpers JJH, Nocera DG. Science. 2011; 334:645-648. [PubMed: 21960528] c) Faunce T, Styring S, Wasielewski MR, Brudvig GW, Rutherford AW, Messinger J, Lee AF, Hill CL, deGroot H, Fontecave M, MacFarlane DR, Hankamer B, Nocera DG, Tiede DM, Dau H, Hillier W, Wang L, Amal R. Energy Environ. Sci. 2013; 6:1074-1076.

[4]. a) Zouni A, Witt HT, Kern J, Fromme P, Krauss N, Saenger W, Orth P. Nature. 2001; 409:739743. [PubMed: 11217865] b) Robblee JH, Cinco RM, Yachandra VK. Biochim. Biophys. Acta Bioenerg. 2001; 1503:7-23.c) Loll B, Kern J, Saenger W, Zouni A, Biesiadka J. Nature. 2005; 438:1040-1044. [PubMed: 16355230] d) Yano J, Kern J, Sauer K, Latimer MJ, Pushkar Y, Biesiadka J, Loll B, Saenger W, Messinger J, Zouni A, Yachandra VK. Science. 2006; 314:821825. [PubMed: 17082458] e) Pushkar Y, Yano J, Sauer K, Boussac A, Yachandra VK. Proc. Natl. Acad. Sci. USA. 2008; 105:1879-1884. [PubMed: 18250316] f) Dau H, Grundmeier A, Loja P, Haumann M. Philos. Trans. R. Soc. London Ser. B. 2008; 363:1237-1243. [PubMed: 17989002] g) Guskov A, Kern J, Gabdulkhakov A, Broser M, Zouni A, Saenger W. Nat. Struct. Mol. Biol. 2009; 16:334-342. [PubMed: 19219048]

[5]. Umena Y, Kawakami K, Shen J-R, Kamiya N. Nature. 2011; 473:55-60. [PubMed: 21499260]

[6]. a) Luber S, Rivalta I, Umena Y, Kawakami K, Shen J-R, Kamiya N, Brudvig GW, Batista VS. Biochemistry. 2011; 50:6308-6311. [PubMed: 21678908] b) Ames W, Pantazis DA, Krewald V, Cox N, Messinger J, Lubitz W, Neese F. J. Am. Chem. Soc. 2011; 133:19743-19757. [PubMed: 22092013] c) Galstyan A, Robertazzi A, Knapp EW. J. Am. Chem. Soc. 2012; 134:7442-7449. [PubMed: 22489676]

[7]. Siegbahn PEM. J. Am. Chem. Soc. 2009; 131:18238-18239. [PubMed: 19961231] 
[8]. a) Dismukes GC, Siderer Y. Proc. Natl. Acad. Sci. USA. 1981; 78:274-278. [PubMed: 16592949] b) Brudvig GW, Casey JL, Sauer K. Biochim. Biophys. Acta Bioenerg. 1983; 723:366-371.c) Casey JL, Sauer K. Biochim. Biophys. Acta Bioenerg. 1984; 767:21-28.d) Zimmermann J-L, Rutherford AW. Biochim. Biophys. Acta Bioenerg. 1984; 767:160-167.e) De Paula JC, Brudvig GW. J. Am. Chem. Soc. 1985; 107:2643-2648.f) De Paula JC, Innes JB, Brudvig GW. Biochemistry. 1985; 24:8114-8120. [PubMed: 3004575] g) Hansson Ö, Aasa R, Vänngård T. Biophys. J. 1987; 51:825-832. [PubMed: 19431697] h) Haddy A, Aasa R, Andr asson L-E. Biochemistry. 1989; 28:6954-6959.i) Bonvoisin J, Blondin G, Girerd J-J, Zimmermann J-L. Biophys. J. 1992; 61:1076-1086. [PubMed: 19431827] j) hrling KA, Pace RJ. Biophys. J. 1995; 68:2081-2090. [PubMed: 7612851] k) Boussac A, Girerd J-J, Rutherford AW. Biochemistry. 1996; 35:6984-6989. [PubMed: 8679522] 1) Boussac A, Un S, Horner O, Rutherford AW. Biochemistry. 1998; 37:4001-4007. [PubMed: 9565450] m) Boussac A, Kuhl H, Un S, Rçgner M, Rutherford AW. Biochemistry. 1998; 37:8995-9000. [PubMed: 9636042] n) Geijer P, Dek Z, Styring S. Biochemistry. 2000; 39:6763-6772. [PubMed: 10841755] o) Zhang C, Styring S. Biochemistry. 2003; 42:8066-8076. [PubMed: 12834358] p) Kulik LV, Epel B, Lubitz W, Messinger J. J. Am. Chem. Soc. 2007; 129:13421-13435. [PubMed: 17927172] q) Su J-H, Cox N, Ames W, Pantazis DA, Rapatskiy L, Lohmiller T, Kulik LV, Dorlet P, Rutherford AW, Neese F, Boussac A, Lubitz W, Messinger J. Biochim. Biophys. Acta Bioenerg. 2011; 1807:829-840.

[9]. Haddy A. Photosynth. Res. 2007; 92:357-68. [PubMed: 17551843]

[10]. a) Ho FM. Biochim. Biophys. Acta Bioenerg. 2012; 1817:10-120.b) Lundberg M, Siegbahn PEM. Chem. Phys. Lett. 2005; 401:347-351.c) Siegbahn PEM. Inorg. Chem. 2008; 47:17791786. [PubMed: 18330969] d) Siegbahn PEM. Acc. Chem. Res. 2009; 42:1871-1880. [PubMed: 19856959] e) Siegbahn PEM. Phys. Chem. Chem. Phys. 2012; 14:4849-4856. [PubMed: 22278436]

[11]. Pantazis DA, Ames W, Cox N, Lubitz W, Neese F. Angew. Chem. 2012; 124:1007410079.Angew. Chem. Int. Ed. 2012; 51:9935-9940.

[12]. Mattioli G, Risch M, Amore Bonapasta A, Dau H, Guidoni L. Phys. Chem. Chem. Phys. 2011; 13:15437-15441. [PubMed: 21808773]

[13]. a) Sproviero EM, Gascón JA, McEvoy JP, Brudvig GW, Batista VS. J. Am. Chem. Soc. 2008; 130:3428-3442. [PubMed: 18290643] b) Sproviero EM, Shinopoulos K, Gascón JA, McEvoy JP, Brudvig GW, Batista VS. Philos. Trans. R. Soc. London Ser. B. 2008; 363:1149-1156. [PubMed: 17971333] c) Saito K, Rutherford AW, Ishikita H. Proc. Natl. Acad. Sci. USA. 2013; 110:954-959. [PubMed: 23277574] d) Saito K, Rutherford AW, Ishikita H. Proc. Natl. Acad. Sci. USA. 2013; 110:7690-7695. [PubMed: 23599284] e) Colombo MC, Guidoni L, Laio A, Magis-trato A, Maurer P, Piana S, Rçhrig U, Spiegel K, Sulpizi M, VandeVondele J, Zumstein M, Rothlisberger U. Chimia. 2002; 56:13-19.f) Laino T, Mohamed F, Laio A, Parrinello M. J. Chem. Theory Comput. 2005; 1:1176-1184.g) VandeVondele J, Krack M, Mohamed F, Parrinello M, Chassaing T, Hutter J. Comput. Phys. Commun. 2005; 167:103-128.

[14]. Retegan M, Neese F, Pantazis DA. J. Chem. Theory Comput. 2013; 9:3832-3842.

[15]. Cox N, Pantazis DA, Neese F, Lubitz W. Acc. Chem. Res. 2013; 46:1588-1596. [PubMed: 23506074]

[16]. Gatt P, Stranger R, Pace RJ. J. Photochem. Photobiol. B. 2011; 104:80-93. [PubMed: 21396828]

[17]. a) Suzuki H, Sugiura M, Noguchi T. Biochemistry. 2008; 47:11024-11030. [PubMed: 18821774] b) Cox N. J. Messinger, Biochim. Biophys. Acta Bioenerg. 2013; 1827:1020-1030.

[18]. Siegbahn PEM. J. Am. Chem. Soc. 2013; 135:9442-9449. [PubMed: 23742698]

[19]. Rapatskiy L, Cox N, Savitsky A, Ames WM, Sander J, Nowaczyk MM, Rögner M, Boussac A, Neese F, Messinger J, Lubitz W. J. Am. Chem. Soc. 2012; 134:16619-16634. [PubMed: 22937979] 


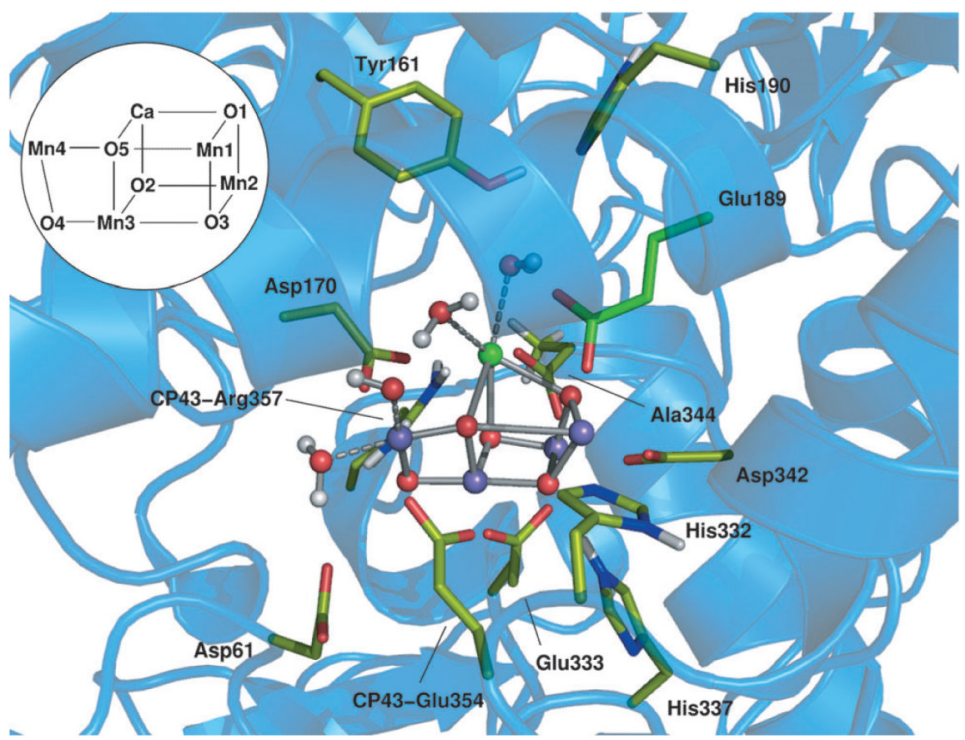

Figure 1.

Snapshot of the oxygen-evolving complex in its PSII environment from DFT+ U ab initio molecular dynamics at the quantum mechanics/molecular mechanics level. A selection of the atoms considered is represented by solid sticks and spheres. Green C, red O, blue N purple balls $\mathrm{Mn}$, green ball $\mathrm{Ca}$, gray $\mathrm{H}$. 


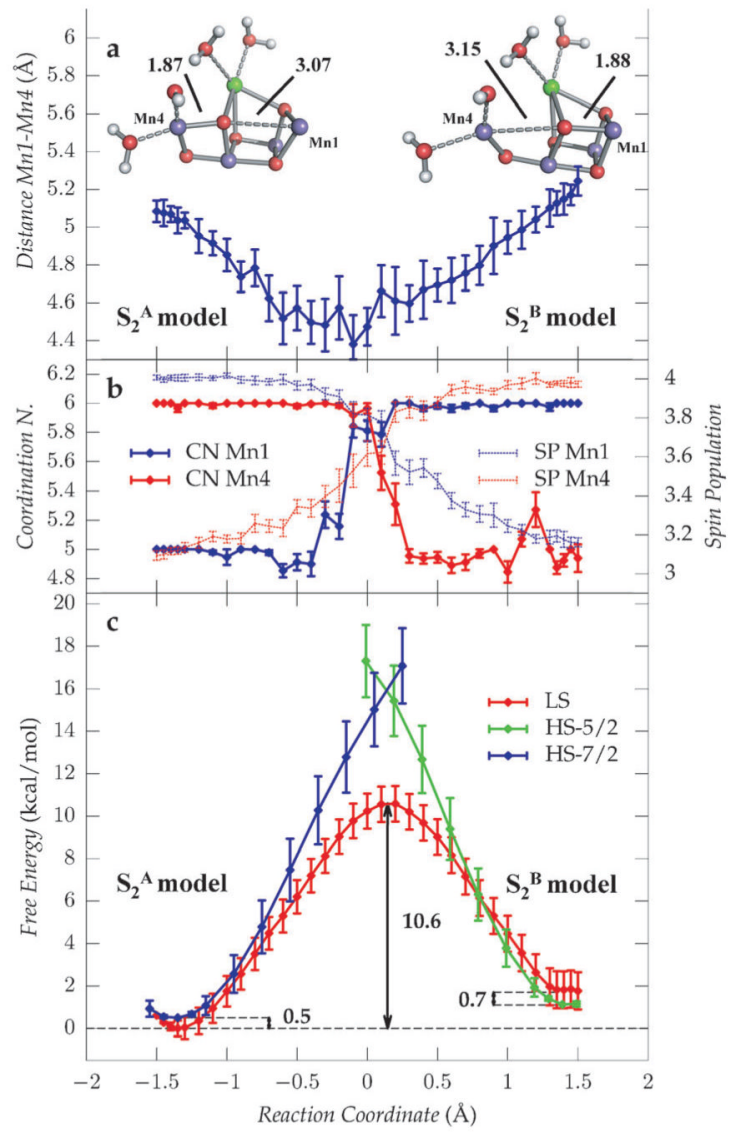

Figure 2.

Geometric, electronic, and thermodynamic properties of the OEC along the interconversion path between the $\mathrm{S}_{2}{ }^{\mathrm{A}}$ and the $\mathrm{S}_{2}{ }^{\mathrm{B}}$ states. a) Average Mn1-Mn4 distance extracted from each $\mathrm{QM} / \mathrm{MM}$ ab initio MD trajectory used in the calculation of the LS free-energy surface. b) Spin populations (SP; dashed lines) and coordination numbers (CN; solid lines) for Mn4 (red) and Mn1 (blue). c) Free-energy profiles of the low-spin (red) and high-spin (blue, green) surfaces. 
a $g=4.1$ signal High Spin (HS)
Low Spin (LS)

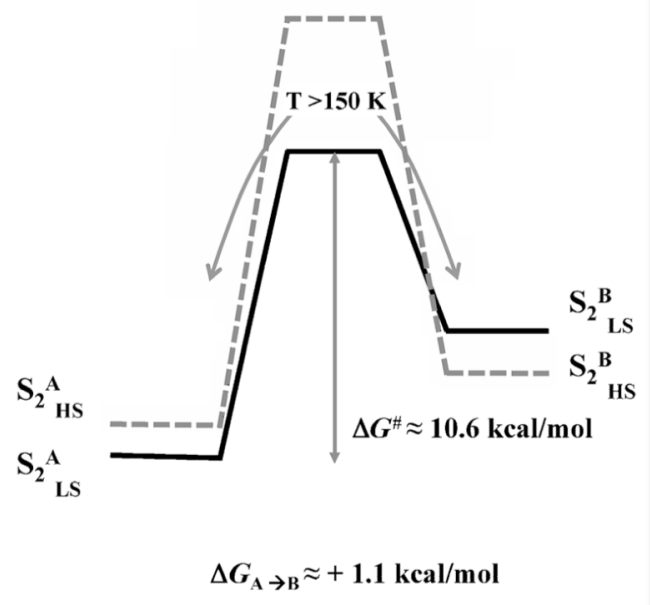

b

1) $T=$ 200-220 K Illumination

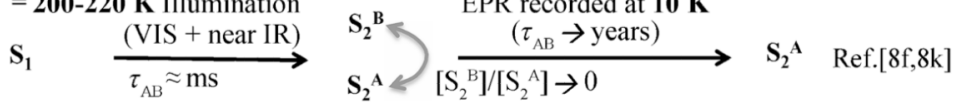

2) $T=130-140$ K Illumination

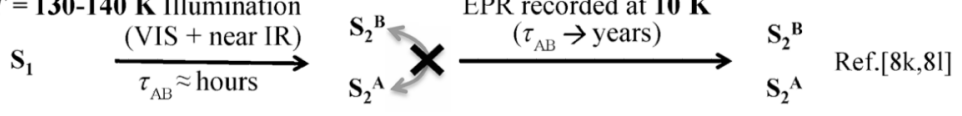

3) $T=130-140 \mathrm{~K}$

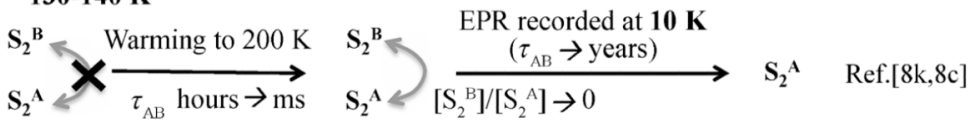

4) $T=130 \mathrm{~K} \quad$ Illumination $\quad$ EPR recorded at $10 \mathrm{~K}$

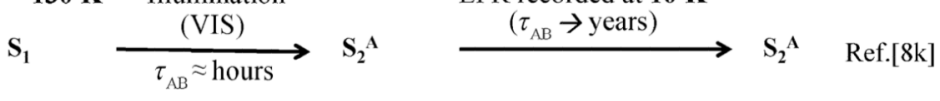

5) $T=130 \mathrm{~K}$ IR illumination

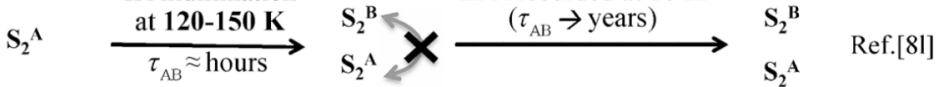

6) $T=130 \mathrm{~K} \quad$ EPR recorded at $10 \mathrm{~K}$

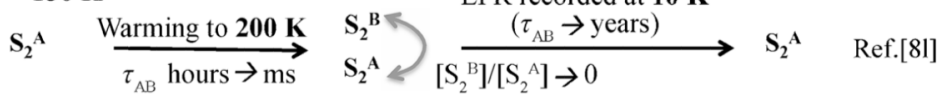

Figure 3.

Energy landscape of the $\mathrm{S}_{2}{ }^{\mathrm{A}}$ and $\mathrm{S}_{2}{ }^{\mathrm{B}}$ transition suggests an interpretation for the dependence of EPR experiments on temperature, illumination conditions, and procedures. a) The thermodynamic and kinetic parameters for the $\mathrm{S}_{2}{ }^{\mathrm{A}}$ to $\mathrm{S}_{2}{ }^{\mathrm{B}}$ transition in the LS (solid line) and HS (dashed line) states. b) Proposed interpretation of the several experiments involving the passage between the two EPR signals in $S_{2}$. 


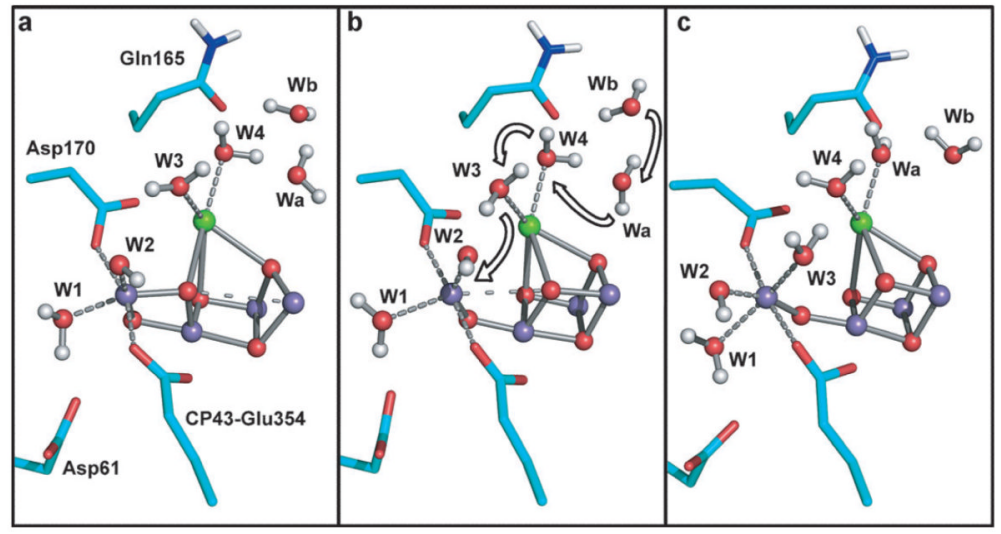

Figure 4.

Possible pathway for the substrate water as obtained by ab initio MD calculations: a) Representative structure of $\mathrm{S}_{2}{ }^{\mathrm{A}}$. b) Representative structure of $\mathrm{S}_{2}{ }^{\mathrm{B}}$. c) Representative structure of a configuration with all the manganese ions hexacoordinate. 